\title{
Comparison of common perioperative blood loss estimation techniques: a systematic review and meta-analysis
}

\author{
Lara Gerdessen ${ }^{1} \cdot$ Patrick Meybohm $^{1,2} \cdot$ Suma Choorapoikayil $^{1} \cdot$ Eva Herrmann $^{3} \cdot$ Isabel Taeuber $^{1} \cdot$ Vanessa Neef $^{1}$. \\ Florian J. Raimann ${ }^{1} \cdot$ Kai Zacharowski ${ }^{1} \cdot$ Florian Piekarski $^{1}$ [D
}

Received: 17 May 2020 / Accepted: 11 August 2020 / Published online: 19 August 2020

(c) The Author(s) 2020

\begin{abstract}
Estimating intraoperative blood loss is one of the daily challenges for clinicians. Despite the knowledge of the inaccuracy of visual estimation by anaesthetists and surgeons, this is still the mainstay to estimate surgical blood loss. This review aims at highlighting the strengths and weaknesses of currently used measurement methods. A systematic review of studies on estimation of blood loss was carried out. Studies were included investigating the accuracy of techniques for quantifying blood loss in vivo and in vitro. We excluded nonhuman trials and studies using only monitoring parameters to estimate blood loss. A meta-analysis was performed to evaluate systematic measurement errors of the different methods. Only studies that were compared with a validated reference e.g. Haemoglobin extraction assay were included. 90 studies met the inclusion criteria for systematic review and were analyzed. Six studies were included in the meta-analysis, as only these were conducted with a validated reference. The mixed effect meta-analysis showed the highest correlation to the reference for colorimetric methods (0.93 95\% CI 0.91-0.96), followed by gravimetric (0.77 95\% CI 0.61-0.93) and finally visual methods $(0.6195 \%$ CI 0.40-0.82). The bias for estimated blood loss (ml) was lowest for colorimetric methods (57.59 95\% CI 23.88-91.3) compared to the reference, followed by gravimetric (326.36 95\% CI 201.65-450.86) and visual methods (456.51 95\% CI 395.19-517.83). Of the many studies included, only a few were compared with a validated reference. The majority of the studies chose known imprecise procedures as the method of comparison. Colorimetric methods offer the highest degree of accuracy in blood loss estimation. Systems that use colorimetric techniques have a significant advantage in the real-time assessment of blood loss.
\end{abstract}

Keywords Blood loss estimation · Visual estimation · Gravimetric method · Patient blood management · Direct measurement . Colorimetric blood loss estimation

Electronic supplementary material The online version of this article (https://doi.org/10.1007/s10877-020-00579-8) contains supplementary material, which is available to authorized users.

Florian Piekarski

florian.piekarski@kgu.de

1 Department of Anaesthesiology, Intensive Care Medicine and Pain Therapy, University Hospital Frankfurt, Goethe University Frankfurt, Theodor-Stern-Kai 7, 60590 Frankfurt am Main, Germany

2 Department of Anaesthesia and Critical Care, University Hospital Würzburg, Würzburg, Germany

3 Institute of Biostatistics and Mathematical Modelling, Department of Medicine, Goethe University, Frankfurt, Germany

\begin{tabular}{|c|c|}
\hline \multicolumn{2}{|l|}{ Abbreviations } \\
\hline Acrobat-NRSI & A Cochrane Risk of Bias Assessment \\
\hline & $\begin{array}{l}\text { Tool: for Non- Randomized Studies of } \\
\text { Interventions }\end{array}$ \\
\hline CEUS & Contrast-enhanced ultrasound \\
\hline $\mathrm{cSO}_{2}$ & $\mathrm{Hb}$ saturation of left frontal lobe \\
\hline FET & Feature Extraction Technology \\
\hline $\mathrm{Hb}$ & Haemoglobin \\
\hline $\mathrm{HbD}$ & Oxygenation index \\
\hline Het & Hematocrit values \\
\hline ICSH & $\begin{array}{l}\text { International Council for Standardization } \\
\text { in Haematology }\end{array}$ \\
\hline OSTHEO & $\begin{array}{l}\text { Orthopedic Surgery Transfusion Haemo- } \\
\text { globin European Overview }\end{array}$ \\
\hline PBM & Patient Blood Management \\
\hline PPH & Postpartum hemorrhage \\
\hline $\mathrm{pSO}_{2}$ & $\mathrm{Hb}$ saturation of left calf \\
\hline
\end{tabular}




$\begin{array}{ll}\text { QBL } & \text { Quantification of Blood Loss } \\ \text { RBC } & \text { Red blood cell units } \\ \text { RoB } & \text { Risk of Bias } \\ \text { SD } & \text { Standard deviation } \\ \text { USD } & \text { US Dollar }\end{array}$

\section{Introduction}

Estimating intraoperative blood loss is a daily challenge of clinicians and until now a standardized method is not being used routinely. Despite the knowledge of the inaccuracy of visual estimation, intraoperative blood loss is still recorded visually $[1,2]$. However, the quantified blood loss plays a key role in blood transfusion decisions, along with other information such as hemoglobin values and individual transfusion triggers. Inappropriate transfusion of blood products is associated with risks and influences patient's outcome [3, 4]. Changes in vital and laboratory parameters recorded during routine monitoring only occur in the event of imminent or manifest hemodynamic instability and organ perfusion diminution.

Especially in obstetrics, estimating blood loss is challenging, as amniotic fluid erroneously causes the impression of high blood loss. In addition, the volume of external blood loss is also difficult to estimate [5, 6]. It is noteworthy that loss of lower blood volumes is estimated more correctly than loss of higher blood volumes. However, large blood loss is life-threatening and therefore more relevant in transfusion decisions [7-9]. Other methods for recording intraoperative blood loss such as pictograms or direct measurement, are rarely used [1]. As part of various programs, the weighing of contaminated material, the so-called gravimetric method, was introduced as a supplement [2,10-13]. However, the direct measurement by using calibrated collection bags is not used in the operating theatre, whereas this method has long been practiced during childbirth [14].

Within the framework of Patient Blood Management (PBM) as a multidisciplinary and evidence-based treatment concept [4], the recording of blood loss is becoming increasingly important. PBM is based on three main pillars: (1) Anaemia management, (2) Minimizing blood loss and increased use of donor blood saving strategies, (3) Rational use of blood reserves [15]. Reducing blood loss and optimizing patient care starts with the measurement of intraoperative blood loss.

Recently developed methods, such as photometric analysis, are becoming more popular in clinical practice. Three systematic reviews $[2,14,16]$ have been published on blood loss estimation in obstetrics. Since then, new approaches and methods have been developed, however, none of these reviews addressed the setting of the operation theatre. This review and meta-analysis are intended to show a range of measurement methods and to highlight the strengths and weaknesses of the methods used within surgery.

\section{Methods}

The protocol of this systematic review was registered in PROSPERO 2020 CRD42020166803 (https://www.crd.york. ac.uk/PROSPERO).

\subsection{Data sources and search strategy}

The research was carried out using PubMed and Google Scholar databases. Only studies published between 01.01.2000-11.11.2019 in English or German language were considered. This period has been chosen to include primarily current literature with more recent reference methods. The results were merged using the reference management software Citavi 6 (Version 6.3.0.0, Swiss Academic Software GmbH, Wädenswil, Schweiz). For the advanced search on PubMed, synonyms of the word blood loss (blood loss, haemoglobin loss, fluid management) were combined with synonyms of the word measurement (estimate*, measurement, evaluation, determinat*, quantification, quantify, assessment, monitoring). With the feature "Show similar articles" the search has been extended. For the Google Scholar Search, the above stated method refining the PubMed search was also used. Two independent reviewers (LG and FP) screened all abstracts for inclusion and exclusion criteria.

Studies were included investigating the accuracy of techniques for quantifying blood loss in vivo and in vitro. We excluded nonhuman trials and studies using only monitoring parameters to estimate blood loss. Finally, we excluded comments or letters to the editor. Full texts of all selected studies were read and analyzed.

\subsection{Assessment of bias}

Two reviewers (LG and FP) independently assessed the quality of the included primary studies using the Acrobat-NRSI tool published by the Cochrane Collaboration (https://www. cochrane.de/de/rob-manual). This quality assessment tool evaluates non-randomized studies for bias due to confounders (1), by selecting participants into study groups, (2), by recording the intervention of the performance (3), by deviations in the intervention phase (4), by missing data (5), by endpoint survey (6) and by selective reporting of endpoints (7). After answering the predefined questions for each of the domains, the reviewers have assessed the bias potential for each domain according to the following classification: low Risk of Bias (RoB) "++" (study is comparable to a randomized study); moderate RoB "+" (study correctly 
performed represents a non-randomized study); significant RoB "-" (study has some serious problems); critical RoB "-_" (study has too many serious problems); unclear RoB "?" (due to lack of information, no assessment is possible). The overall rating of a non-randomized study is based on the domain with the highest RoB.

\subsection{Meta-analytical procedures}

A meta-analysis was performed to evaluate systematic measurement errors of the different methods. All studies were screened using reference method "hemoglobin extraction assay". Included in the meta-analysis were studies that used this valid method as reference. The hemoglobin extraction assay is a laborious and therefore an accurate method for quantifying blood volume. In this procedure, blood-soaked products are rinsed and examined to determine the hemoglobin concentration spectrophotometrically [17]. Studies with incomplete data concerning a Bland-Altman analysis were secondarily excluded.

\subsection{Statistical analysis}

Statistical analyses were carried out with the metafor Package: A Meta-Analysis Package for R (version 2.4-0, Free Software Foundation Inc., Boston, USA) [18]. For the individual studies, the systematic bias \pm standard deviation (SD) was extracted from the given Bland Altman analyses. Confidence intervals of bias in the individual studies were calculated. The total bias estimated value with total confidence interval was calculated. The upper and lower tolerance limits were determined. $\mathrm{I}^{2}$ statistics were computed to quantify the heterogeneity. If significant heterogeneity of results was found (defined as $\mathrm{I}^{2}>50 \%$ ), we investigated the relationship between this result and the predefined variables outlined above using meta-regression analysis.

Given the heterogeneity of the studies examined in the review, the approach of modelling random effects was used to merge the result data.

\section{Results}

\subsection{Study identification}

The advanced search on PubMed produced a total of 7877 results. The function "Shows similar articles" identified another 158 potentially relevant studies. After reviewing the titles of 8035 studies, 7747 studies were primarily excluded. Of the 288 potentially relevant studies, all studies involving children or animals were excluded secondarily, as well as those studies that used only vital parameters as an indication of anaemia. Therefore, a total of 140 studies were left for full-text review. Finally, 50 further studies were excluded due to: no availability of the full text; letters or comments to the editor; young participants under 18 years of age; the measurement of intraoperative blood loss not primarily addressed and primarily investigation of measurement accuracy of an instrument compared to the laboratory. A total of 90 studies were included in the systematic review (Supplement 1) and six studies were included in the metaanalysis (Fig. 1). The main reason for exclusion was the lack of comparison with a validated reference method.

\subsection{Risk of bias assessment}

The assessment regarding the risk of bias of the individual studies is presented in detail in Table 1. The risk of bias due to confounders was increased in the majority of the studies. The selection of participants in study groups showed an increased risk of bias in four studies [19-22] and an unclear risk of bias in two studies [23, 24]. The documentation and endpoint assessment were adequately described in most of the studies. A deviation in the intervention phase was not described in any of the studies. The handling of missing data was not adequately described in most studies, so that an unclear risk of bias was found. Double-blinding was found in only a few studies. The risk of selective reporting was low in all except four studies [25-28]. The overall methodological quality of the studies reviewed was rather low and the overall risk of bias across the studies was high.

\subsection{Used methods within surgery or obstetrics}

Based on the studies, we examined the methods according to various criteria. The advantages and disadvantages of the individual methods are summarized in Fig. 2.

\subsubsection{Visual estimation}

The visual estimation of blood loss by clinicians is not only one of the most widely used methods, but also the most examined one. This includes the estimation of blood volumes in sponges and suction containers but also the recording of external blood losses. Forty-eight studies dealt with the accuracy and improvement of visual assessment and 29 of these were performed in obstetrics. The study results are heterogeneous, so there are different results about the influence of different factors of professional experience, gender, age on the accuracy of the estimate. Even the use of pictograms and other measures does not lead to clear improvements (for a detailed description of the various studies, please refer to Supplement 2) [29-39]. 


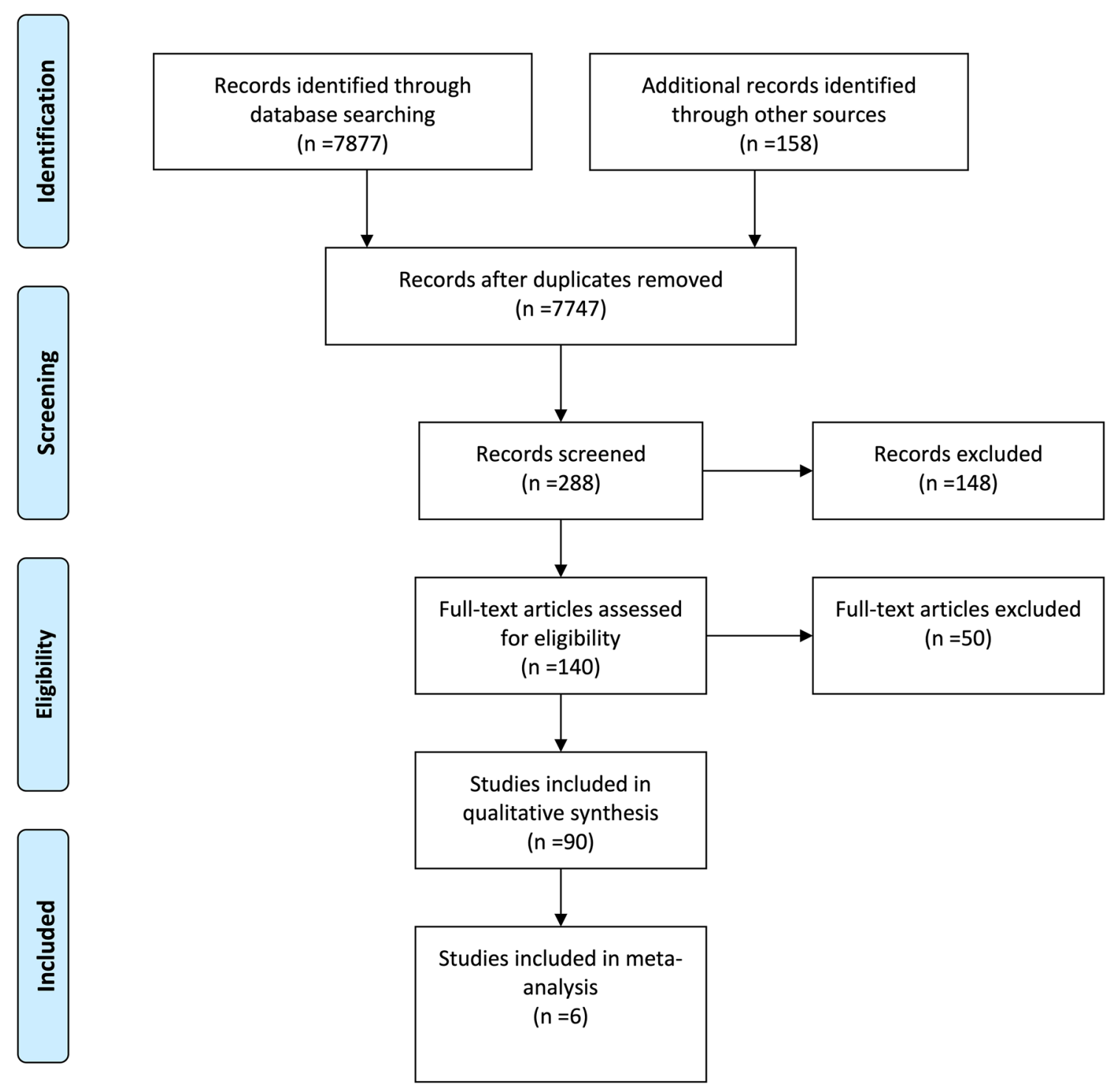

Fig. 1 PRISMA flow diagram. From: Moher D, Liberati A, Tetzlaff J, Altman DG, The PRISMA Group (2009). Preferred Reporting Items for Systematic Reviews and Meta-Analyses: The PRISMA Statement.

\subsubsection{Gravimetric}

The gravimetric method is an indirect measurement of blood loss. Blood loss can be deduced by weighing the surgical material contaminated with blood and subtracting the dry weights. By summing up the measured weight of the blood and estimating the amount $(\mathrm{ml})$ of mixed liquids (e.g. blood, rinse liquid) in the suction container, the blood loss can be calculated with a conversion of $1 \mathrm{~g}=1 \mathrm{ml}$ blood $[38,66]$. The study results for gravimetric methods show a higher degree of correlation but are nevertheless heterogenic. Especially the factor of increased dilution by amniotic fluid or rinsing are relevant factors that lead to inaccuracy in the calculation $[27,67,68]$ (for a detailed
PLoS Med 6(7): e1000097. 10.1371/journal.pmed1000097. For more information, visit www.prisma-statement.org

description of the various studies, please refer to Supplement 3).

\subsubsection{Direct measurement}

The direct measurement of blood loss is a simple and longestablished method that is mainly used in the field of obstetrics. Nine studies focused on calibrated collection bags specially designed for vaginal deliveries. The collector bag is placed under the woman's buttocks immediately after the birth of the child and collects all mixed liquids (e.g. blood or amniotic fluid). At the bottom of the plastic foil there is a calibrated collector bag with a scale on which the current blood loss can be read. This method is easy to use and, 


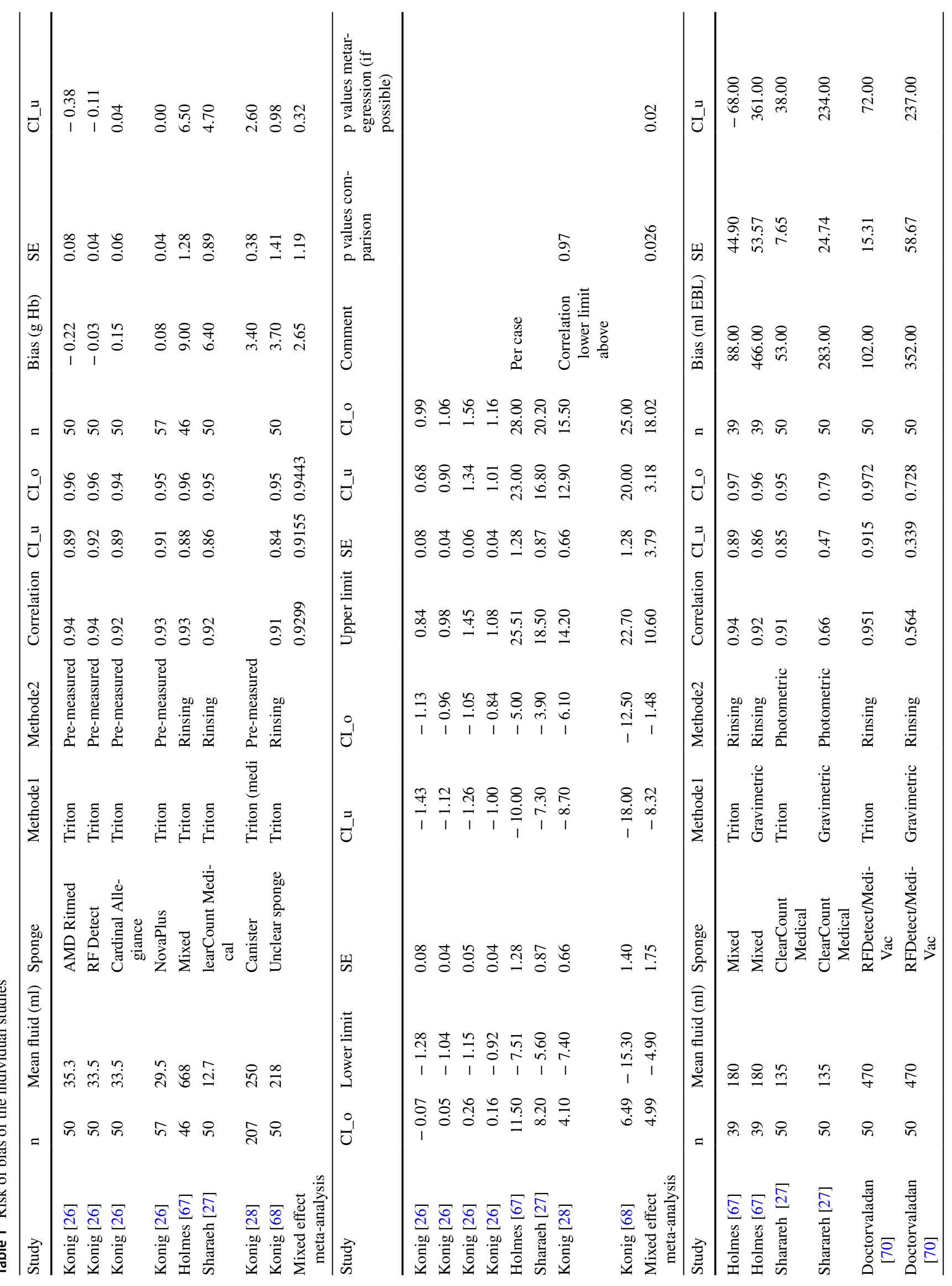




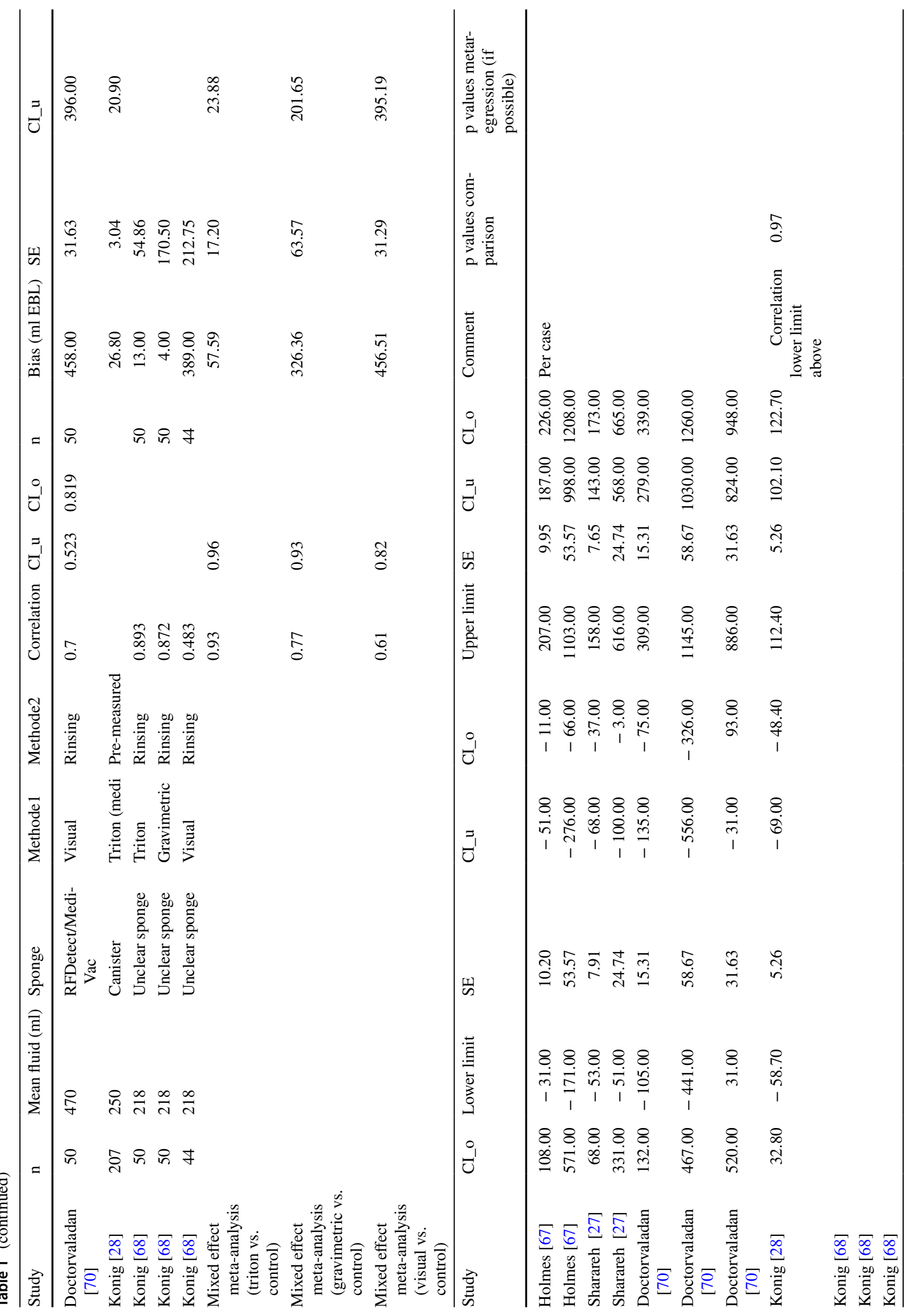


especially in resource-poor areas, in combination with a visual assessment can somewhat improve the quantification of the total blood volume, e.g. during a birth. However, study results still show significant deviations from real blood volume when used [71-75] (for a detailed description of the various studies, please refer to supplement 4).

\subsubsection{Calculated blood loss}

Currently, various mathematical approaches are used in clinical practice to evaluate blood loss. To calculate the most exact intraoperative blood loss, the formula has been modified over time. Thus, three different formulas are used in the literature to calculate the total blood volume of patients. The Moore formula [75, 76], which, like Nadler's formula [75-81] takes into account height, weight and sex for the calculation, and the ICSH formula [75, 76], which uses gender and body surface area to calculate the total blood volume. The formula according to Nadler was used most often in the literature. All blood loss estimation formulas showed a significant tendency to overestimate blood loss. (For a detailed description of the various studies, please refer to supplement 5).

\subsubsection{Colorimetric blood loss estimation}

A smartphone application (Triton ${ }^{\mathrm{TM}}$ ) developed by Gauss Surgical Inc. is able to calculate blood loss by taking photographs of used surgical gauze and canisters. The colorimetric technique analyses photographic and geometric information from relevant areas, with the aim of automatically filtering out the effects of non-blood components mixed in each sponge and canister and calculating the $\mathrm{Hb}$ mass present in the gauze or canister from the image. By entering the preoperative Hb-level, the blood loss can then be calculated. In the studies analyzed, high degrees of correlation with the reference blood volumes were found [22, 24, 26-28, 39, 67, $68,70,83$ ] (For a detailed description of the various studies, please refer to supplement 6).

\subsubsection{Miscellaneous methods}

Other methods for the intraoperative recording of blood loss are rarely described and have not yet been sufficiently tested. Ultrasound of the inferior vena cava [20, 84, 85], contrast enhanced ultrasound (CEUS) [86], hemodynamic esophageal Doppler monitoring [19], near-infrared spectroscopy [87] or continuous non-invasive intraoperative $\mathrm{Hb}$ monitoring $[23,88,89]$ for intraoperative detection of blood loss have been investigated. None of these methods represents a valid technique for blood loss detection. (For a detailed description of the various studies, please refer to supplement 7). 


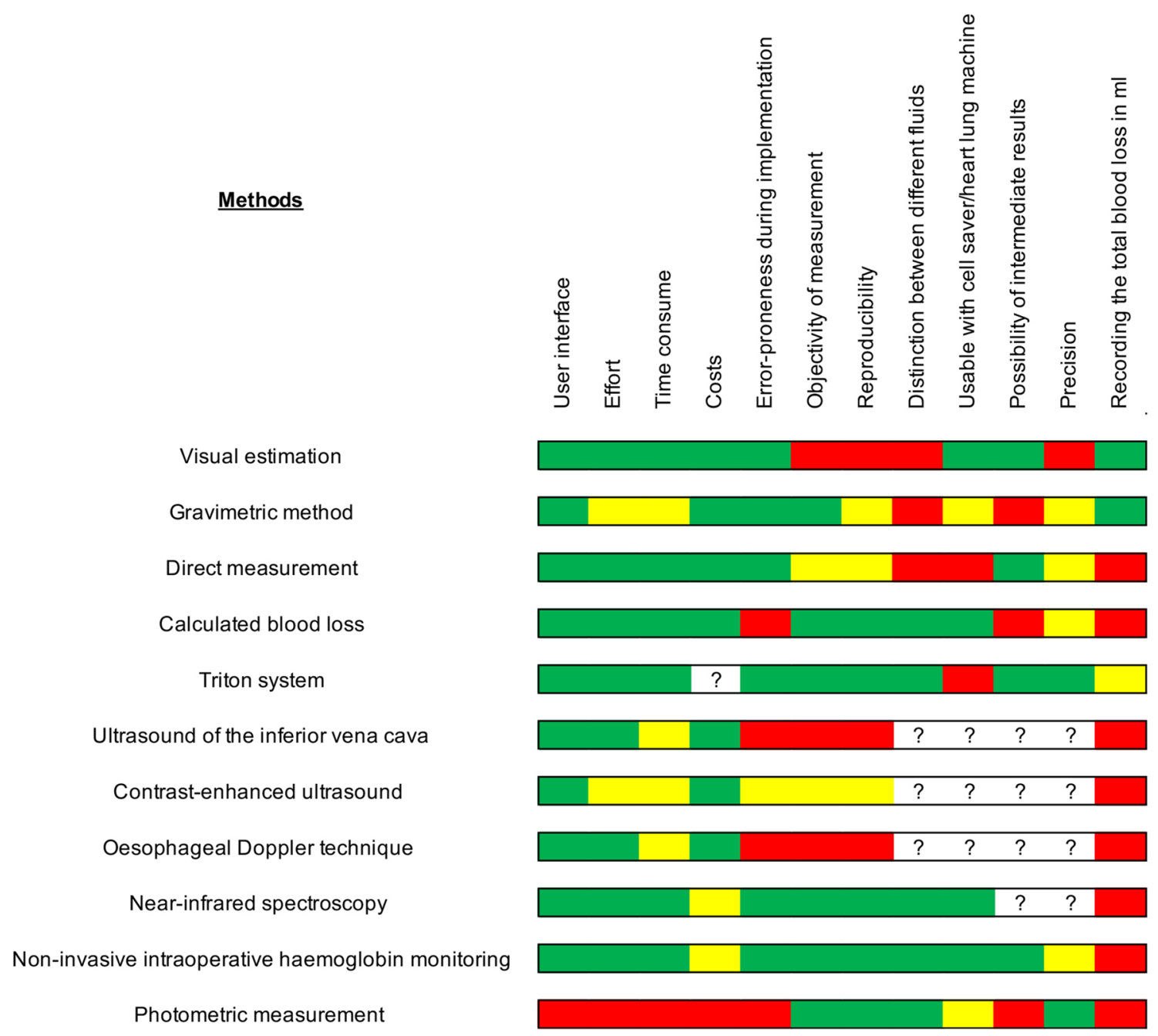

Fig. 2 Pros and cons of blood loss estimation methods. Pros and cons of blood loss estimation methods are presented. Red=extremely poor, yellow $=$ moderate; green $=$ excellent

\subsection{Meta-analysis}

Six studies $[26-28,67,68,70]$ used $\mathrm{Hb}$ assay as a validated reference method and Bland Altman results were available for meta-analysis. The mixed effect meta-analysis showed the highest correlation to the reference for colorimetric methods ( $0.9395 \%$ CI $0.91-0.96)$, followed by gravimetric $(0.7795 \%$ CI $0.61-0.93)$ and finally visual methods $(0.61$ 95\% CI 0.40-0.82) (Table 2). The bias for estimated blood loss (ml) was lowest for colorimetric methods $(57.5995 \%$ CI 23.88-91.3) compared to the reference, followed by gravimetric (326.36 95\% CI 201.65-450.86) and visual methods (456.51 95\% CI 395.19-517.83) (Table 2).

Figure 3 shows the bias of the blood loss [ml] measurements with the colorimetric method compared to the reference. The overall bias estimate is significantly different from zero $(p=0.0008)$. There is no significant increasing trend toward a higher bias for higher mean or median blood loss used in the individual studies $(\mathrm{p}=0.2317)$. The results of the meta-regression analysis show significant heterogeneity $\mathrm{I}^{2}=87.9 \%, \mathrm{p}<0.0001$ and $\mathrm{R}^{2}=15.24 \%$ of the heterogeneity considered in the meta-regression model.

The overall bias of colorimetric estimated blood loss is significantly different from $0(\mathrm{p}=0.026)$. The bias of the $\mathrm{Hb}$ mass [g] measurements with the colorimetric system compared to the reference is shown in Fig. 4. The correlation for colorimetric $\mathrm{Hb}$ measurement correlated strong (0.930 95\% CI 0.96-0.94) with reference $\mathrm{Hb}$. There is a significantly increasing trend toward higher distortion for higher mean or median blood volume used in the individual studies $(p=0.020)$. The results of the meta-regression analysis still show a significant heterogeneity $\mathrm{I}^{2}=99.9 \%$, $\mathrm{p}<0.0001$ and $\mathrm{R}^{2}=53.26 \%$ of the heterogeneity considered in the meta-regression model. 
Table 2 Results of meta-analysis

\begin{tabular}{|c|c|c|c|c|c|c|c|c|c|c|c|c|c|c|c|c|c|}
\hline Author(s) (YearPublished) & 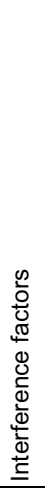 & 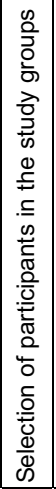 & 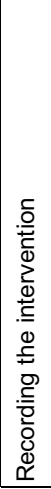 & 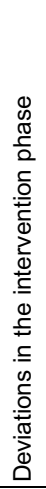 & $\begin{array}{l}\frac{\pi}{\pi} \\
\frac{\pi}{0} \\
0 \\
\frac{.}{w} \\
. \frac{0}{\Sigma} \\
\end{array}$ & 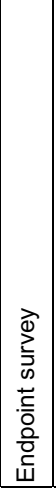 & 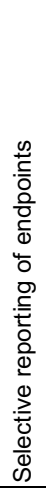 & 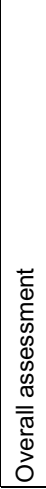 & Author(s) (YearPublished) & 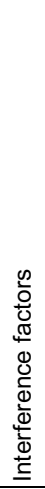 & 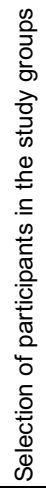 & 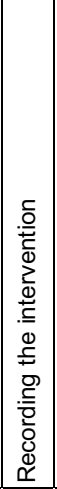 & 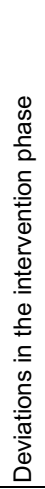 & $\begin{array}{l}\frac{\pi}{\pi} \\
\frac{\pi}{0} \\
\frac{5}{D} \\
\frac{\tilde{D}}{D} \\
\frac{\omega}{\Sigma}\end{array}$ & 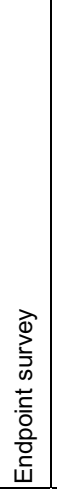 & 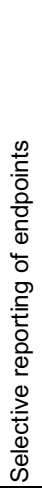 & 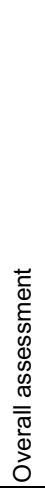 \\
\hline Visual Estimation: testing in Simulations & & & & & & & & & Gravimetric Method & & & & & & & & \\
\hline Meiser et al (2001) & + & 1 & ++ & 1 & + & + & + & + & Ambardekar et al (2014) & + & ++ & + & ++ & + & + & + & + \\
\hline Beer et al (2005) & - & 1 & $?$ & 1 & ? & + & + & $?$ & Lilley et al (2015) & - & 1 & + & I & - & + & + & - \\
\hline Bose et al (2006) & + & I & + & 1 & $?$ & + & + & $?$ & Atukunda et al (2016) & + & ++ & + & ++ & + & + & + & + \\
\hline Buckland et al (2007) & - & 1 & + & 1 & - & + & + & - & Ladouceur et al (2019) & - & 1 & - & 1 & $?$ & + & + & - \\
\hline McConnell et al (2007) & + & 1 & + & 1 & - & + & + & - & Direct Measurement & & & & & & & & \\
\hline Yoong et al (2010) & + & 1 & + & 1 & ? & + & + & $?$ & Strand et al (2003) & - & 1 & - & 1 & $?$ & - & - & - \\
\hline Adkins et al (2014) & + & 1 & + & 1 & + & + & + & + & Patel et al (2006) & + & ++ & + & ++ & $?$ & + & + & $?$ \\
\hline Parayre et al (2015) & - & 1 & + & 1 & $?$ & + & + & - & Toledo et al (2007) & + & ++ & + & ++ & $?$ & + & + & $?$ \\
\hline Rothermel et al (2016) & + & 1 & + & 1 & - & + & + & - & Zhang et al (2010) & - & ++ & - & ++ & $?$ & + & + & - \\
\hline Pranal et al (2018) & - & 1 & + & 1 & - & + & + & - & Tixier et al (2011) & + & 1 & + & 1 & $?$ & + & + & $?$ \\
\hline Kollberg et al (2019) & + & 1 & + & 1 & $?$ & + & + & $?$ & Legendre et al (2016) & - & I & + & 1 & + & + & + & - \\
\hline Visual Estimation: operation Theatre & & & & & & & & & Abbaspoor et al (2017) & - & I & + & 1 & ? & + & + & - \\
\hline Howe et al (2003) & $?$ & 1 & $?$ & 1 & ? & + & + & $?$ & Calculated Blood loss & & & & & & & & \\
\hline McCullough et al (2004) & - & 1 & - & 1 & ? & + & + & - & Hurle et al (2004) & $?$ & 1 & + & 1 & ? & + & + & $?$ \\
\hline Kavle et al (2006) & - & 1 & + & 1 & + & + & + & - & Božičković et al (2011) & - & 1 & + & 1 & $?$ & + & + & - \\
\hline Larsson et al (2006) & - & 1 & + & 1 & $?$ & + & + & - & Milosevic et al (2011) & - & 1 & + & 1 & + & + & + & - \\
\hline Stafford et al (2008) & - & 1 & + & 1 & $?$ & + & + & - & Stahl et al (2012) & + & ++ & + & + & + & + & + & + \\
\hline Wangwe et al (2012) & - & 1 & + & 1 & $?$ & + & + & - & Gao et al (2015) & - & 1 & + & 1 & ? & + & + & - \\
\hline Guinn et al (2013) & + & 1 & + & 1 & $?$ & + & + & $?$ & Lopez-Picardo et al (2017) & + & ++ & + & + & + & + & + & + \\
\hline Ram et al (2014) & - & 1 & + & 1 & $?$ & + & + & - & Kahr et al (2018) & - & 1 & + & 1 & $?$ & + & + & - \\
\hline Conner et al (2015) & - & 1 & + & 1 & ? & + & + & - & Jaramilo et al (2019) & + & 1 & + & 1 & $?$ & + & + & $?$ \\
\hline Lertbunnaphong et al (2016) & - & 1 & + & 1 & $?$ & + & + & - & Triton System & & & & & & & & \\
\hline Withanathantrige et al (2016) & ++ & 1 & + & 1 & + & + & + & + & Holmes et al (2014) & - & 1 & + & 1 & $?$ & + & + & - \\
\hline Budair et al (2017) & + & 1 & + & 1 & + & + & + & + & Konig et al (2014) & + & 1 & - & 1 & $?$ & + & -- & -- \\
\hline Gluck et al (2017) & + & 1 & + & 1 & ? & + & + & ? & Sharareh et al (2015) & + & I & + & 1 & $?$ & + & - & - \\
\hline Hamm et al (2018) & - & 1 & + & 1 & $?$ & + & + & - & Doctorvaladan et al (2017) & + & I & + & 1 & $?$ & + & + & $?$ \\
\hline Serapio et al (2018) & -- & 1 & + & 1 & $?$ & + & + & -- & Thurer et al (2017) & - & - & + & + & $?$ & + & + & - \\
\hline Ulusoy et al (2018) & + & 1 & + & 1 & $?$ & + & + & $?$ & Konig et al (2018) & + & 1 & + & 1 & ? & + & -- & - \\
\hline Anya et al (2019) & - & 1 & + & 1 & $?$ & + & + & - & Konig et al (2018) & + & 1 & + & 1 & $?$ & + & + & $?$ \\
\hline Visual Estimation: Tools and Training & & & & & & & & & Rubenstein et al (2018) & - & $?$ & + & + & ? & + & + & - \\
\hline Dildy et al (2004) & - & l & + & 1 & $?$ & + & + & - & Fedouruk et al (2019) & - & I & + & 1 & $?$ & + & + & - \\
\hline Sukprasert et al (2006) & ++ & + & + & + & $?$ & + & + & $?$ & Saoud et al (2019) & + & I & + & I & ? & + & + & $?$ \\
\hline Maslovitz et al (2008) & - & ++ & + & ++ & - & + & + & - & Miscellaneous Methods & & & & & & & & \\
\hline Merlin et al (2009) & - & 1 & + & 1 & $?$ & + & + & -- & Torella et al (2002) & - & 1 & + & 1 & $?$ & + & + & \\
\hline Toledo et al (2010) & - & - - & + & + & + & + & + & -- & Torella et al (2002) & - & 1 & + & 1 & $?$ & + & + & - \\
\hline Toledo et al (2012) & - & 1 & + & 1 & - & + & + & - & Lyon et al (2005) & - & 1 & + & 1 & $?$ & + & + & - \\
\hline Cheerranichanunth et al (2012) & - & 1 & + & 1 & $?$ & + & + & - & Resnick et al (2011) & - & 1 & + & 1 & + & + & + & - \\
\hline Al-Kadri et al (2014) & - & I & + & 1 & $?$ & + & + & - & Oba et al (2019) & - & - & + & + & $?$ & + & + & - \\
\hline Zuckerwise et al (2014) & - & 1 & + & 1 & $?$ & + & + & - & Oshima et al (2005) & - & I & + & 1 & $?$ & + & + & - \\
\hline Golmakani et al (2015) & - & 1 & + & 1 & $?$ & + & + & - & Meunier et al (2008) & - & $?$ & + & + & $?$ & + & + & - \\
\hline Ali Algadiem et al (2016) & + & 1 & + & 1 & + & + & + & + & Kamal et al (2016) & + & ++ & + & + & + & + & + & + \\
\hline Kordi et al (2016) & + & ++ & + & ++ & + & + & + & + & Mannova et al (2013) & 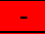 & - & + & + & $?$ & + & + & - \\
\hline Brooks et al (2017) & - & I & + & 1 & $?$ & + & + & - & Imai et al (2017) & - & 1 & + & 1 & $?$ & + & + & - \\
\hline Khadilkar et al (2016) & + & ++ & + & ++ & + & + & + & + & & & & & & & & & \\
\hline Homcha et al (2017) & + & 1 & + & 1 & ? & + & + & $?$ & & & & & & & & & \\
\hline Mbachu et al (2017) & + & 1 & + & 1 & - & + & + & 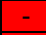 & & & & & & & & & \\
\hline Willcox et al (2017) & - & 1 & + & 1 & + & + & + & - & & & & & & & & & \\
\hline Yeung et al (2017) & - & 1 & + & 1 & + & + & + & & & & & & & & & & \\
\hline Nelson et al (2018) & - & 1 & + & 1 & $?$ & + & + & & & & & & & & & & \\
\hline
\end{tabular}

Risk of bias of the individual studies are presented. low RoB “++" (study is comparable to a randomized study); moderate RoB " + " (study correctly performed represents a non-randomized study); significant RoB “-” (study has some serious problems); critical RoB “--" (study has too many serious problems); unclear RoB "?" (due to lack of information no assessment is possible) 


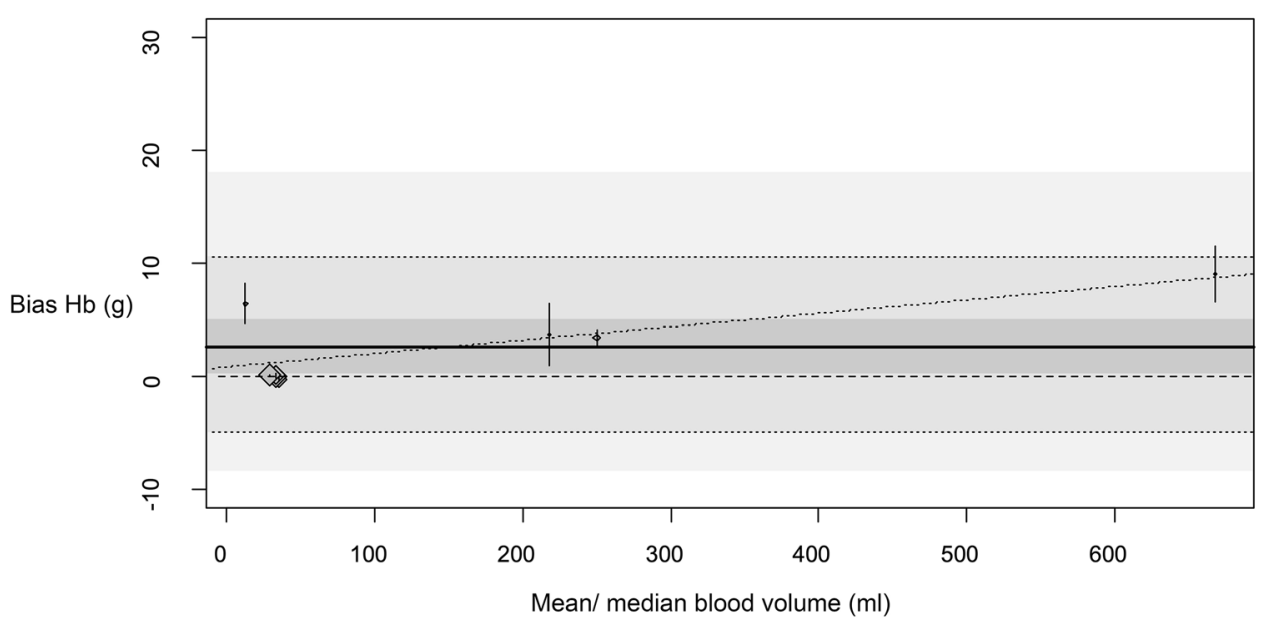

Fig. 3 Bias of $\mathrm{Hb}[\mathrm{g}]$ measurements with colorimetric method. Bias of $\mathrm{Hb}[\mathrm{g}]$ measurements with colorimetric method compared to reference. Diamonds show the bias estimates from the single studies (size of diamonds is inversely related to standard error). Small vertical bars show confidence intervals of bias in the single studies. The darkest grey shaded area is the overall confidence interval for the estimated bias. The thick joined line shows the overall bias estimate. The medium shaded area reaches from the overall estimate of the lower tolerance limit to the overall estimate to the upper tolerance limit, both limits are also indicated by a dotted line. The lightest shaded area reaches from the lower confidence interval limit of the lower tolerance limit to the upper confidence interval limit of the upper tolerance limit

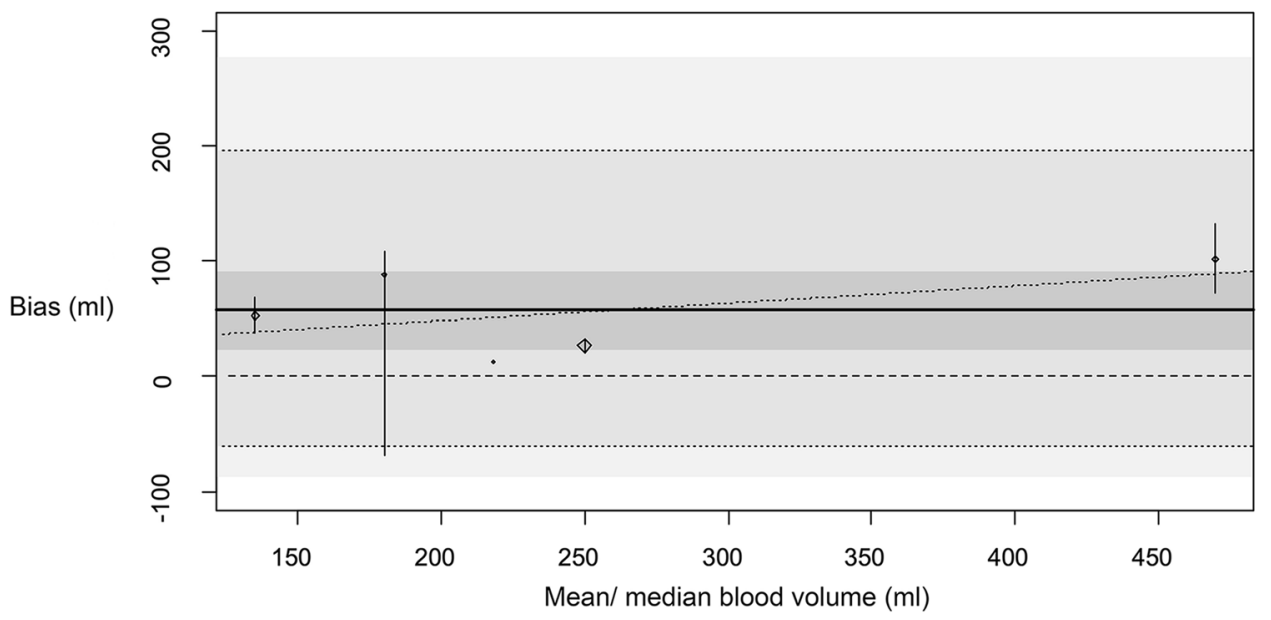

Fig. 4 Bias of blood volume [ml] estimates with colorimetric method. Bias of blood volume [ml] estimated by colorimetric method compared to reference. Diamonds show the bias estimates from the single studies (size of diamonds is inversely related to standard error). Small vertical bars show confidence intervals of bias in the single studies. The darkest grey shaded area is the overall confidence interval for the estimated bias. The thick joined line shows the overall bias

\section{Discussion}

We were able to show in our meta-analysis that the colorimetric blood estimation provides a strong correlation to the reference blood volume. In contrast, gravimetric method or visual estimation shows only a medium estimate. The medium shaded area reaches from the overall estimate of the lower tolerance limit to the overall estimate to the upper tolerance limit, both limits are also indicated by a dotted line. The lightest shaded area reaches from the lower confidence interval limit of the lower tolerance limit to the upper confidence interval limit of the upper tolerance limit

correlation. It was shown that the bias for blood loss in the colorimetric system is significantly lower than in the other methods.

Visual estimation is the most widely used method for recording intraoperative blood loss and can be performed directly in the operating theatre without the need for additional equipment. However, regardless of specialty, 
professional experience or education level, visual estimation is not accurate. The estimation of lost blood volume depends on the physicians and is hard to reproduce. Especially in scenarios with larger bleeding the visual estimation often fails. A clear tendency to over- or underestimation cannot be detected, but either one can lead to wrong decisions in patient care.

The gravimetric method considers external blood loss. Frequently used conversion in literature " $1 \mathrm{~g}$ equals $1 \mathrm{ml}$ of blood" is only an approximation. Blood, depending on the current Hct, does not have the same density as water. Both lead to measurement inaccuracies. The calculation of the lost blood volume is a cost-effective way to quickly provide information about the suspected blood loss. Many of the formulas are based on $\mathrm{Hb}$-value or Hct changes and require normovolaemia to calculate the patient's total blood volume. This assumption can lead to measurement inaccuracies. It is known, that the measurement of the $\mathrm{Hb}$ level through blood gas analysis only shows indications of blood loss after adequate volume therapy and is therefore delayed. This can also lead to measurement inaccuracies. The result is independent of the user and easy to apply, especially if a user-friendly program is used for support.

The latest innovative method to detect blood loss is the colorimetric estimation technique. Our meta-analysis revealed a strong correlation to reference blood volume. The overall bias estimate shows that the systematic bias is within the $30 \mathrm{~g} \mathrm{Hb}$ mass, which was defined as the clinically relevant limit. Thirty grams Hb-mass corresponds to approximately $1 / 10$ of a whole blood unit. External blood loss cannot be taken into account by the system. If a cell saver or the heart-lung machine is involved, the system can only be used partially because the calibration of the canisters required for the colorimetric system is not sterile.

\subsection{Limitations}

We have identified several limitations for this review and meta-analysis. The selected reference methods differ widely and are usually not considered to be sufficiently valid themselves. There is no gold standard reference for recording intraoperative blood loss. The sample size of the individual studies was mostly small. Most of the studies were prospective observational studies without doubleblinding and control group. The risk of bias and heterogeneity for the individual studies was high. Although many studies are available in this area, one weakness of most studies is that no validated reference was used for comparison. Many studies compare themselves with other equally inaccurate methods. This underlines the need for more high-quality large-scale studies in this area.

\section{Conclusion}

The recording of intraoperative blood loss plays a very central role in the daily routine of clinicians. Based on these estimations, patient's treatment and transfusion decisions are made. Consequently, for the patient safety, we should aim fort the highest possible accuracy of measurement. Visually and gravimetric blood loss estimation measurements show a high degree of bias, so its usage cannot be recommended. Colorimetric technology offers real-time measurement and has a high degree of correlation.

Acknowledgements Open Access funding provided by Projekt DEAL. Please verify relation to: Johann Wolfgang Goethe-Universität, Frankfurt am Main (1022).

Author contributions LG helped with substantial contributions to the conception and design of the work; the acquisition, analysis, and interpretation of the data for the work; drafting the work; and wrote the manuscript. PM helped with substantial contributions to the acquisition; revising it critically for important intellectual content; and final approval of the version to be published. SC helped with substantial contributions to the acquisition; revising it critically for important intellectual content; and final approval of the version to be published. EH helped with substantial contributions to the conception and design of the work; interpretation of the data for the work; revising it critically for important intellectual content. IT helped edit the manuscript. VN helped with editing and revising the manuscript critically for important intellectual content. FJR helped with editing and revising the manuscript critically for important intellectual content. KZ helped with implementing the study and editing and revising the manuscript critically for important intellectual content. FP helped with substantial contributions to the conception and design of the work; the acquisition, analysis, and interpretation of the data for the work; and edit the manuscript.

\section{Compliance with ethical standards}

Conflict of interest The authors declared that they have no conflict of interest.

Open Access This article is licensed under a Creative Commons Attribution 4.0 International License, which permits use, sharing, adaptation, distribution and reproduction in any medium or format, as long as you give appropriate credit to the original author(s) and the source, provide a link to the Creative Commons licence, and indicate if changes were made. The images or other third party material in this article are included in the article's Creative Commons licence, unless indicated otherwise in a credit line to the material. If material is not included in the article's Creative Commons licence and your intended use is not permitted by statutory regulation or exceeds the permitted use, you will need to obtain permission directly from the copyright holder. To view a copy of this licence, visit http://creativecommons.org/licenses/by/4.0/.

\section{References}

1. Piekarski F, Wunderer F, Raimann FJ, Neef V, Peuckert M, Brenner T, Grottke O, Grünewald M, Gürtler K, Renner J, Thal 
S, Seyfried T, Zacharowski K, Meybohm P, Kollaborateure. Erfassung von intraoperativen Blutverlusten. Ergebnisse einer multizentrischen Erhebung und Überblick aktueller Methoden zur Quantifizierung von Blutverlusten. Anästh Intensivmed 2020;61:110-6. https://doi.org/10.19224/ai2020.110.

2. Gabel KT, Weeber TA. Measuring and communicating blood loss during obstetric hemorrhage. J Obstet Gynecol Neonatal Nurs. 2012;41:551-8. https://doi.org/10.1111/j.1552-6909.2012.01375 .X.

3. Querschnitts-Leitlinien zur Therapie mit Blutkomponenten und Plasmaderivaten (2009) Mit 19 Tabellen, 4th edn. Dt. Ärzte-Verl., Köln

4. Müller MM, Meybohm P, Geisen C, Schmitz-Rixen T, Serve H, Seifried E, Zacharowski K. Patient blood management-Wie geht das praktisch?-Die interdisziplinäre Zusammenarbeit. Anasthesiol Intensivmed Notfallmed Schmerzther. 2014;49:266-72. https ://doi.org/10.1055/s-0034-1373806.

5. Mbachu II, Udigwe GO, Ezeama CO, Eleje GU, Eke AC. Effect of on-site training on the accuracy of blood loss estimation in a simulated obstetrics environment. Int J Gynaecol Obstet. 2017;137:345-9. https://doi.org/10.1002/ijgo.12133.

6. Buckland SS, Homer CSE. Estimating blood loss after birth: using simulated clinical examples. Women Birth. 2007;20:85-8. https ://doi.org/10.1016/j.wombi.2007.01.001.

7. Al-Kadri HM, Dahlawi H, Al Airan M, Elsherif E, Tawfeeq $\mathrm{N}$, Mokhele $\mathrm{Y}$, et al. Effect of education and clinical assessment on the accuracy of post partum blood loss estimation. BMC Pregnancy Childbirth. 2014;14:110. https://doi. org/10.1186/1471-2393-14-110.

8. Ram G-G, Suresh P, Vijayaraghavan P-V. Surgeons often underestimate the amount of blood loss in replacement surgeries. Chin J Traumatol. 2014;17:225-8.

9. Parayre I, Rivière O, Debost-Legrand A, Lémery D, Vendittelli F. Reliability of student midwives' visual estimate of blood loss in the immediate postpartum period: a cross-sectional study. Int J Nurs Stud. 2015;52:1798-803. https://doi.org/10.1016/j.ijnur stu.2015.06.015.

10. Golmakani N, Khaleghinezhad K, Dadgar S, Hashempor M, Baharian N. Comparing the estimation of postpartum hemorrhage using the weighting method and National Guideline with the postpartum hemorrhage estimation by midwives. Iran J Nurs Midwifery Res. 2015;20:471-5. https://doi.org/10.4103/17359066.161005.

11. Larsson C, Saltvedt S, Wiklund I, Pahlen S, Andolf E. Estimation of blood loss after cesarean section and vaginal delivery has low validity with a tendency to exaggeration. Acta Obstet Gynecol Scand. 2006;85:1448-522. https://doi.org/10.1080/0001634060 0985032.

12. Ladouceur MK, Goldbort J. A proactive approach to quantification of blood loss in the perinatal setting. Nurs Womens Health. 2019. https://doi.org/10.1016/j.nwh.2019.09.007.

13. Hamm RF, Wang E, Romanos A, O'Rourke K, Srinivas SK. Implementation of quantification of blood loss does not improve prediction of hemoglobin drop in deliveries with average blood loss. Am J Perinatol. 2018;35:134-9. https://doi.org/10.1055/s-0037-16062 75.

14. Schorn MN. Measurement of blood loss: review of the literature. J Midwifery Womens Health. 2010;55:20-7. https://doi. org/10.1016/j.jmwh.2009.02.014.

15. Althoff FC, Neb H, Herrmann E, Trentino KM, Vernich L, Füllenbach $\mathrm{C}$, et al. Multimodal patient blood management program based on a three-pillar strategy: a systematic review and metaanalysis. Ann Surg. 2019;269:794-804. https://doi.org/10.1097/ SLA.0000000000003095.

16. Hancock A, Weeks AD, Lavender DT. Is accurate and reliable blood loss estimation the 'crucial step' in early detection of postpartum haemorrhage: an integrative review of the literature. BMC Pregnancy Childbirth. 2015;15:230. https://doi.org/10.1186/ s12884-015-0653-6.

17. Keenan WN, Griffiths H, Clegg J. Evaluating blood loss in children's orthopaedic surgery: a simplified method of photometric analysis of eluted swabs. J Pediatr Orthop. 1998;18:488-91.

18. Viechtbauer W. Conducting meta-analyses in $\mathrm{R}$ with the metafor package. J Stat Softw. 2010. https://doi.org/10.18637/jss.v036.i03.

19. Mannova JH, Silhart Z, Sevcik P, Prokes A. Perioperative haemodynamic monitoring by oesophageal Doppler improves outcome of patients with abdominal aortic aneurysm repair. Bratisl Lek Listy. 2013;114:78-83.

20. Oba T, Koyano M, Hasegawa J, Takita H, Arakaki T, Nakamura $\mathrm{M}$, Sekizawa A. The inferior vena cava diameter is a useful ultrasound finding for predicting postpartum blood loss. J Matern Fetal Neonatal Med. 2019;32:3251-4. https://doi.org/10.1080/14767 058.2018.1462321.

21. Toledo P, McCarthy RJ, Burke CA, Goetz K, Wong CA, Grobman WA. The effect of live and web-based education on the accuracy of blood-loss estimation in simulated obstetric scenarios. Am J Obstet Gynecol. 2010;202(400):e1-5. https://doi. org/10.1016/j.ajog.2009.10.881.

22. Thurer RL, Castro JM, Javidroozi M, Burton K, Bernal NP. Accurate measurement of intraoperative blood loss improves prediction of postoperative hemoglobin levelsAccurate measurement of intraoperative blood loss improves prediction of postoperative hemoglobin levels. J Anesth Clin Res. 2017. https ://doi.org/10.4172/2155-6148.1000743.

23. Meunier A, Petersson A, Good L, Berlin G. Validation of a haemoglobin dilution method for estimation of blood loss. Vox Sang. 2008;95:120-4. https://doi.org/10.111 1/j.1423-0410.2008.01071.x.

24. Rubenstein AF, Zamudio S, Al-Khan A, Douglas C, Sledge S, Tully G, Thurer RL. Clinical experience with the implementation of accurate measurement of blood loss during cesarean delivery: influences on hemorrhage recognition and allogeneic transfusion. Am J Perinatol. 2018;35:655-9. https://doi. org/10.1055/s-0037-1613675.

25. Strand RT, da Silva F, Bergström S. Use of cholera beds in the delivery room: a simple and appropriate method for direct measurement of postpartum bleeding. Trop Doct. 2003;33:215-6. https://doi.org/10.1177/004947550303300408.

26. Konig G, Holmes AA, Garcia R, Mendoza JM, Javidroozi M, Satish S, Waters JH. In vitro evaluation of a novel system for monitoring surgical hemoglobin loss. Anesth Analg. 2014;119:595-600. https://doi.org/10.1213/ANE.0000000000 000198 .

27. Sharareh B, Woolwine S, Satish S, Abraham P, Schwarzkopf R. Real time intraoperative monitoring of blood loss with a novel tablet application. Open Orthop J. 2015;9:422-6. https://doi. org/10.2174/1874325001509010422.

28. Konig G, Waters JH, Hsieh E, Philip B, Ting V, Abbi G, et al. In vitro evaluation of a novel image processing device to estimate surgical blood loss in suction canisters. Anesth Analg. 2018;126:621-8. https://doi.org/10.1213/ANE.000000000000269 2.

29. Lilley G, Burkett-St-Laurent D, Precious E, Bruynseels D, Kaye A, Sanders J, et al. Measurement of blood loss during postpartum haemorrhage. Int J Obstet Anesth. 2015;24:8-14. https://doi. org/10.1016/j.ijoa.2014.07.009.

30. Kollberg SE, Häggström A-CE, Lingehall HC, Olofsson B. Accuracy of visually estimated blood loss in surgical sponges by members of the surgical team. AANA J. 2019;87:277-84.

31. Anya SU, Onyekwulu FA, Onuora EC. Comparison of visual estimation of intra-operative blood loss with haemoglobin estimation 
in patients undergoing caesarean section. Niger Postgrad Med J. 2019;26:25-30. https://doi.org/10.4103/npmj.npmj_164_18.

32. Homcha BE, Mets EJ, Goldenberg MDF, Kong L, Vaida SJ. Development and assessment of pictorial guide for improved accuracy of visual blood loss estimation in cesarean delivery. Simul Healthc. 2017;12:314-8. https://doi.org/10.1097/SIH.0000000000 000246.

33. Kordi M, Fakari FR, Mazloum SR, Khadivzadeh T, Akhlaghi F, Tara M. Comparison of the effect of web-based, simulation-based, and conventional training on the accuracy of visual estimation of postpartum hemorrhage volume on midwifery students: a randomized clinical trial. J Educ Health Promot. 2016;5:22. https:// doi.org/10.4103/2277-9531.184548.

34. Adkins AR, Lee D, Woody DJ, White WA. Accuracy of blood loss estimations among anesthesia providers. AANA J. 2014;82:300-6.

35. Yoong W, Karavolos S, Damodaram M, Madgwick K, Milestone $\mathrm{N}, \mathrm{Al}-\mathrm{Habib} \mathrm{A}$, et al. Observer accuracy and reproducibility of visual estimation of blood loss in obstetrics: how accurate and consistent are health-care professionals? Arch Gynecol Obstet. 2010;281:207-13. https://doi.org/10.1007/s00404-009-1099-8.

36. Dildy GA, Paine AR, George NC, Velasco C. Estimating blood loss: can teaching significantly improve visual estimation? Obstet Gynecol. 2004;104:601-6. https://doi.org/10.1097/01.AOG.00001 37873.07820 .34 .

37. Meiser A, Casagranda O, Skipka G, Laubenthal H. Quantifizierung von Blutverlusten. Wie genau ist visuelles Schätzen und wovon hängt die Genauigkeit ab? Anaesthesist 2001;50:13-20. https://doi.org/10.1007/s001010050957

38. Khadilkar SS, Sood A, Ahire P. Quantification of peri-partum blood loss: training module and clot conversion factor. J Obstet Gynaecol India. 2016;66:307-14. https://doi.org/10.1007/s1322 4-016-0888-9.

39. Fedoruk K, Seligman KM, Carvalho B, Butwick AJ. Assessing the association between blood loss and postoperative hemoglobin after cesarean delivery: a prospective study of 4 blood loss measurement modalities. Anesth Analg. 2019;128:926-32. https://doi. org/10.1213/ANE.0000000000003449.

40. Rothermel LD, Lipman JM. Estimation of blood loss is inaccurate and unreliable. Surgery. 2016;160:946-53. https://doi. org/10.1016/j.surg.2016.06.006.

41. McConnell JS, Fox TJ, Josson JP, Subramanian A. "About a cupful"- a prospective study into accuracy of volume estimation by medical and nursing staff. Accid Emerg Nurs. 2007;15:101-5. https://doi.org/10.1016/j.aaen.2007.02.006.

42. McCullough TC, Roth JV, Ginsberg PC, Harkaway RC. Estimated blood loss underestimates calculated blood loss during radical retropubic prostatectomy. Urol Int. 2004;72:13-6. https://doi. org/10.1159/000075266.

43. Bose P, Regan F, Paterson-Brown S. Improving the accuracy of estimated blood loss at obstetric haemorrhage using clinical reconstructions. BJOG. 2006;113:919-24. https://doi.org/10.11 11/j.1471-0528.2006.01018.x.

44. Withanathantrige M, Goonewardene M, Dandeniya R, Gunatilake $\mathrm{P}$, Gamage S. Comparison of four methods of blood loss estimation after cesarean delivery. Int J Gynaecol Obstet. 2016;135:515. https://doi.org/10.1016/j.ijgo.2016.03.036.

45. Budair B, Ahmed U, Hodson J, David M, Ashraf M, McBride T. Are we all guilty of under-estimating intra-operative blood loss during hip fracture surgery? J Orthop. 2017;14:81-4. https://doi. org/10.1016/j.jor.2016.10.019.

46. Kavle JA, Khalfan SS, Stoltzfus RJ, Witter F, Tielsch JM, Caulfield LE. Measurement of blood loss at childbirth and postpartum. Int J Gynaecol Obstet. 2006;95:24-8. https://doi.org/10.1016/j. ijgo.2006.06.010.
47. Howe C, Paschall C, Panwalkar A, Beal J, Potti A. A model for clinical estimation of perioperative hemorrhage. Clin Appl Thromb Hemost. 2003;9:131-5. https://doi.org/10.1177/10760 2960300900207.

48. Guinn NR, Broomer BW, White W, Richardson W, Hill SE. Comparison of visually estimated blood loss with direct hemoglobin measurement in multilevel spine surgery. Transfusion. 2013;53:2790-4. https://doi.org/10.1111/trf.12119.

49. Conner SN, Tuuli MG, Colvin R, Shanks AL, Macones GA, Cahill AG. ACCURACY of estimated blood loss in predicting need for transfusion after delivery. Am J Perinatol. 2015;32:1225-300. https://doi.org/10.1055/s-0035-1552940.

50. Serapio ET, Pearlson GA, Drey EA, Kerns JL. Estimated versus measured blood loss during dilation and evacuation: an observational study. Contraception. 2018;97:451-5. https://doi. org/10.1016/j.contraception.2018.01.008.

51. Pranal M, Guttmann A, Ouchchane L, Parayre I, Rivière O, Leroux S, et al. Do estimates of blood loss differ between student midwives and midwives? A multicenter cross-sectional study. Midwifery. 2018;59:17-22. https://doi.org/10.1016/j. midw.2017.12.017.

52. Lertbunnaphong T, Lapthanapat N, Leetheeragul J, Hakularb P, Ownon A. Postpartum blood loss: visual estimation versus objective quantification with a novel birthing drape. Singap Med J. 2016;57:325-8. https://doi.org/10.11622/smedj.2016107.

53. Stafford I, Dildy GA, Clark SL, Belfort MA. Visually estimated and calculated blood loss in vaginal and cesarean delivery. Am J Obstet Gynecol. 2008;199(519):e1-7. https://doi.org/10.1016/j. ajog.2008.04.049.

54. Beer HL, Duvvi S, Webb CJ, Tandon S. Blood loss estimation in epistaxis scenarios. J Laryngol Otol. 2005;119:16-8. https://doi. org/10.1258/0022215053222752.

55. Maslovitz S, Barkai G, Lessing JB, Ziv A, Many A. Improved accuracy of postpartum blood loss estimation as assessed by simulation. Acta Obstet Gynecol Scand. 2008;87:929-34. https://doi. org/10.1080/00016340802317794.

56. Sukprasert M, Choktanasiri W, Ayudhya NIN, Promsonthi $\mathrm{P}$, O-Prasertsawat P. Increase accuracy of visual estimation of blood loss from education programme. J Med Assoc Thai. 2006;89(Suppl 4):S54-S5959.

57. Toledo P, Eosakul ST, Goetz K, Wong CA, Grobman WA. Decay in blood loss estimation skills after web-based didactic training. Simul Healthc. 2012;7:18-211. https://doi.org/10.1097/ SIH.0b013e318230604f.

58. Yeung CY, Yim WW, Chan SY, Lo RSL, Leung LY, Hung $\mathrm{KKC}$, Graham CA. Improvement of blood loss volume estimation by paramedics using a pictorial nomogram: a developmental study. Injury. 2017;48:2693-8. https://doi.org/10.1016/j.injur y.2017.10.045.

59. Wilcox L, Ramprasad C, Gutierrez A, Oden M, Richards-Kortum R, Sangi-Haghpeykar H, Gandhi M. Diagnosing postpartum hemorrhage: a new way to assess blood loss in a low-resource setting. Matern Child Health J. 2017;21:516-23. https://doi.org/10.1007/ s10995-016-2135-5.

60. Ali Algadiem E, Aleisa AA, Alsubaie HI, Buhlaiqah NR, Algadeeb JB, Alsneini HA. Blood loss estimation using gauze visual analogue. Trauma Mon. 2016;21:e34131. https://doi. org/10.5812/traumamon.34131.

61. Zuckerwise LC, Pettker CM, Illuzzi J, Raab CR, Lipkind HS. Use of a novel visual aid to improve estimation of obstetric blood loss. Obstet Gynecol. 2014;123:982-6. https://doi.org/10.1097/ AOG.0000000000000233.

62. Cheerranichanunth P, Poolnoi P. Using blood loss pictogram for visual blood loss estimation in cesarean section. J Med Assoc Thai. 2012;95:550-6. 
63. Merlin MA, Alter SM, Raffel B, Pryor PW. External blood loss estimation using the MAR Method. Am J Emerg Med. 2009;27:1085-90. https://doi.org/10.1016/j.ajem.2008.07.039.

64. Nelson NC, Ostby SA, Weaver AL, McGree ME, Gebhart JB, Bakkum-Gamez JN. Estimated blood loss during vaginal hysterectomy and adnexal surgery described with an intraoperative pictographic tool. Female Pelvic Med Reconstr Surg. 2018;24:347-51. https://doi.org/10.1097/SPV.0000000000000470.

65. Brooks M, Legendre G, Brun S, Bouet P-E, Mendes LP, Merlot $B$, Sentilhes L. Use of a visual aid in addition to a collector bag to evaluate postpartum blood loss: a prospective simulation study. Sci Rep. 2017;7:46333. https://doi.org/10.1038/srep46333.

66. Ambardekar S, Shochet T, Bracken H, Coyaji K, Winikoff B. Calibrated delivery drape versus indirect gravimetric technique for the measurement of blood loss after delivery: a randomized trial. BMC Pregnancy Childbirth. 2014;14:276. https://doi. org/10.1186/1471-2393-14-276.

67. Holmes AA, Konig G, Ting V, Philip B, Puzio T, Satish S, Waters JH. Clinical evaluation of a novel system for monitoring surgical hemoglobin loss. Anesth Analg. 2014;119:588-94. https://doi. org/10.1213/ANE.0000000000000181.

68. Konig G, Waters JH, Javidroozi M, Philip B, Ting V, Abbi G, et al. Real-time evaluation of an image analysis system for monitoring surgical hemoglobin loss. J Clin Monit Comput. 2018;32:303-10. https://doi.org/10.1007/s10877-017-0016-0.

69. Atukunda EC, Mugyenyi GR, Obua C, Atuhumuza EB, Musinguzi N, Tornes YF, et al. Measuring post-partum haemorrhage in low-resource settings: the diagnostic validity of weighed blood loss versus quantitative changes in hemoglobin. PLoS ONE. 2016;11:e0152408. https://doi.org/10.1371/journal.pone.0152408.

70. Doctorvaladan SV, Jelks AT, Hsieh EW, Thurer RL, Zakowski MI, Lagrew DC. Accuracy of blood loss measurement during cesarean delivery. AJP Rep. 2017;7:e93-e100. https://doi. org/10.1055/s-0037-1601382.

71. Patel A, Goudar SS, Geller SE, Kodkany BS, Edlavitch SA, Wagh $\mathrm{K}$, et al. Drape estimation vs. visual assessment for estimating postpartum hemorrhage. Int J Gynaecol Obstet. 2006;93:220-4. https://doi.org/10.1016/j.ijgo.2006.02.014.

72. Zhang W-H, Deneux-Tharaux C, Brocklehurst P, Juszczak E, Joslin M, Alexander S. Effect of a collector bag for measurement of postpartum blood loss after vaginal delivery: cluster randomised trial in 13 European countries. BMJ. 2010;340:c293. https://doi. org/10.1136/bmj.c293.

73. Tixier H, Boucard C, Ferdynus C, Douvier S, Sagot P. Interest of using an underbuttocks drape with collection pouch for early diagnosis of postpartum hemorrhage. Arch Gynecol Obstet. 2011;283:25-9. https://doi.org/10.1007/s00404-009-1265-z.

74. Legendre G, Richard M, Brun S, Chancerel M, Matuszewski S, Sentilhes L. Evaluation by obstetric care providers of simulated postpartum blood loss using a collector bag: a French prospective study. J Matern Fetal Neonatal Med. 2016;29:3575-81. https:// doi.org/10.3109/14767058.2016.1139569.

75. Lopez-Picado A, Albinarrate A, Barrachina B. Determination of perioperative blood loss: accuracy or approximation? Anesth Analg. 2017;125:280-6. https://doi.org/10.1213/ANE.00000 00000001992.

76. Jaramillo S, Montane-Muntane M, Capitan D, Aguilar F, Vilaseca A, Blasi A, Navarro-Ripoll R. Agreement of surgical blood loss estimation methods. Transfusion. 2019;59:508-15. https://doi. org/10.1111/trf.15052.

77. Hurle R, Poma R, Maffezzini M, Manzetti A, Piccinelli A, Taverna $\mathrm{G}$, et al. A simple mathematical approach to calculate blood loss in radical prostatectomy. Urol Int. 2004;72:135-9. https://doi. org/10.1159/000075967.
78. Božičković N, Popović J, Kolak R, Popović K, Popović D. Application of one-compartmental bio-metric blood loss calculations with transfused blood volume taken into account after aneurysmectomy. Eur J Drug Metab Pharmacokinet. 2011;36:103-8. https ://doi.org/10.1007/s13318-011-0025-1.

79. Milosevic N, Popovic J, Grujic Z, Rapaic M. One-compartmental biometric blood loss calculation after cesarean section. Eur J Drug Metab Pharmacokinet. 2011;36:183-8. https://doi.org/10.1007/ s13318-011-0042-0.

80. Stahl DL, Groeben H, Kroepfl D, Gautam S, Eikermann M. Development and validation of a novel tool to estimate peri-operative blood loss. Anaesthesia. 2012;67:479-86. https://doi.org/10.111 1/j.1365-2044.2011.06916.x.

81. Kahr MK, Brun R, Zimmermann R, Franke D, Haslinger C. Validation of a quantitative system for real-time measurement of postpartum blood loss. Arch Gynecol Obstet. 2018;298:1071-7. https ://doi.org/10.1007/s00404-018-4896-0.

82. Gao F-Q, Li Z-J, Zhang K, Sun W, Zhang H. Four methods for calculating blood-loss after total knee arthroplasty. Chin Med J. 2015;128:2856-60. https://doi.org/10.4103/0366-6999.168041.

83. Saoud F, Stone A, Nutter A, Hankins GD, Saade GR, Saad AF. Validation of a new method to assess estimated blood loss in the obstetric population undergoing cesarean delivery. Am J Obstet Gynecol. 2019;221:267.e1-.e6. https://doi.org/10.1016/j. ajog.2019.06.022.

84. Lyon M, Blaivas M, Brannam L. Sonographic measurement of the inferior vena cava as a marker of blood loss. Am J Emerg Med. 2005;23:45-50. https://doi.org/10.1016/j.ajem.2004.01.004.

85. Resnick J, Cydulka R, Platz E, Jones R. Ultrasound does not detect early blood loss in healthy volunteers donating blood. J Emerg Med. 2011;41:270-5. https://doi.org/10.1016/j.jemer med.2010.11.040.

86. Imai K, Kotani T, Tsuda H, Nakano T, Hirakawa A, Kikkawa F. A novel approach to detecting postpartum hemorrhage using contrast-enhanced ultrasound. Ultrasound Med Biol. 2017;43:615-20. https://doi.org/10.1016/j.ultrasmedbio.2016.11.008.

87. Torella F, Cowley R, Thorniley MS, McCollum CN. Monitoring blood loss with near infrared spectroscopy. Comp Biochem Physiol Part A Mol Integr Physiol. 2002;132:199-203. https://doi. org/10.1016/s1095-6433(01)00548-7.

88. Oshima M, Shimada Y, Takeuchi H, Kinoshita K. Blood loss estimation during laparoscopic myomectomy using HemoCue. J Nippon Med Sch. 2005;72:226-9. https://doi.org/10.1272/ jnms.72.226.

89. Kamal AM, Elramely MA, Abd Elhaq MM. The value of continuous noninvasive hemoglobin monitoring in intraoperative blood transfusion practice during abdominal cancer surgery. OJAnes. 2016;06:13-9. https://doi.org/10.4236/ojanes.2016.63003.

90. Torella F, Cowley RD, Thorniley MS, McCollum CN. Regional tissue oxygenation during hemorrhage: can near infrared spectroscopy be used to monitor blood loss? Shock. 2002;18:440-4. https ://doi.org/10.1097/00024382-200211000-00009.

91. Moher D, Liberati A, Tetzlaff J, Altman DG, The PRISMA Group. Preferred reporting items for systematic reviews and meta-analyses: the PRISMA statement. PLoS Med. 2009;6(7):e1000097. https://doi.org/10.1371/journal.pmed1000097.

Publisher's Note Springer Nature remains neutral with regard to jurisdictional claims in published maps and institutional affiliations. 